\title{
New data on the distal tarsals in Ornithomimidae
}

\author{
Rachel E. Nottrodt and Andrew A. Farke \\ Acta Palaeontologica Polonica 66 (4), 2021: $789-796$ doi:https://doi.org/10.4202/app.00884.2021
}

The ankle in non-avian theropod dinosaurs consists of the astragalus and calcaneum proximally and a distal series of tarsal bones capping the metatarsals. Nearly all theropods have only two distal tarsals, identified as distal tarsal 3 and distal tarsal 4. Historically, the morphology and anatomical relationships of these distal tarsals is uncertain in ornithomimosaurs due to loss and/or disarticulation; even in articulated specimens, the bones can be difficult to access. A previously undescribed ornithomimid fossil from the Kaiparowits Formation (upper Campanian) of southern Utah, USA, provides unique views of the distal tarsals in articulation with their surrounding elements, allowing the most complete assessment yet of this region in an ornithomimid from North America. Distal tarsal 3 contacts both metatarsals II and III, whereas distal tarsal 4 contacts only metatarsal IV. Distal tarsal 4 also shows a tab-like process that projects laterally. Comparison of the new fossil with other ornithomimosaurs shows that distal tarsals in Ornithomimosauria can be generalized as: (i) paired as distal tarsals 3 and 4; (ii) not fused to one another or to the proximal metatarsus; and (iii) proximo-distally compressed. The distal tarsals of ornithomimosaurs vary in the antero-posterior positioning and extent to which they cover the proximal metatarsal surface.

Key words: Theropoda, Ornithomimosauria, Ornithomimidae, tarsals, ankle.

Rachel E. Nottrodt [rachel.nottrodt@ucalgary.ca], University of Calgary, 2500

University Drive NW, Calgary, Alberta, T2N 1N4 Canada. Andrew A. Farke [afarke@webb.org], Raymond M. Alf Museum of Paleontology at The Webb Schools, 1175 Base Line Rd. Claremont, California, 91711 USA.

This is an open-access article distributed under the terms of the Creative Commons Attribution License (for details please see creativecommons.org), which permits unrestricted use, distribution, and reproduction in any medium, provided the original author and source are credited. 
FoF Full text $(733.9 \mathrm{kB})$ 